\title{
RECEIVED
}

JUN 281996

OSTI

\section{Progress Report on Colloid-Facilitated}

Transport at Yucca Mountain

Yucca Mountain Site Characterization Program Milestone 3383

\section{MASTER}

\section{Los Alamos}

NATIONAL LABORATORY

Los Alamos National Laboratory is operated by the University of California for the United States Department of Energy under contract W-7405-ENG-36. 
This work was supported by the Yucca Mountain Site Characterization Project Office as part of the Civilian Radioactive Waste Management Program of the U.S. Department of Energy. The Los Alamos data tracking number for this record package is LA000000000128.001.

An Affirmative Action/Equal Opportunity Employer

This report was prepared as an account of work sponsored by an agency of the United States Government. Neither The Regents of the University of California, the United States Government nor any agency thereof, nor any of their employees, makes any warranty, express or implied, or assumes any legal liability or responsibility for the accuracy, completeness, or usefulness of any information, apparatus, product, or process disclosed, or represents that its use would not infringe privately owned rights. Reference herein to any specific commercial product, process, or service by trade name, trademark, manufacturer, or otherwise, does not necessarily constitute or imply its endorsement, recommendation, or favoring by The Regents of the University of California, the United States Government, or any agency thereof. The views and opinions of authors expressed herein do not necessarily state or reflect those of The Regents of the University of California, the United States Government, or any agency thereof. The Los Alamos National Laboratory strongly supports academic freedom and a researcher's right to publish; therefore, the Laboratory as an institution does not endorse the viewpoint of a publication or guarantee its technical correctness. 
UC-814

Issued: June 1996

Progress Report on Colloid-Facilitated

Transport at Yucca Mountain

Yucca Mountain Site Characterization Program

Milestone 3383

I. R. Triay

C. Degueldre*

A. O. Wistrom ${ }^{* *}$

C. R. Cotter

W. W. Lemons

*Paul Scherrer Institute, Villigen PSI, Switzerland

**University of California, Riverside, California

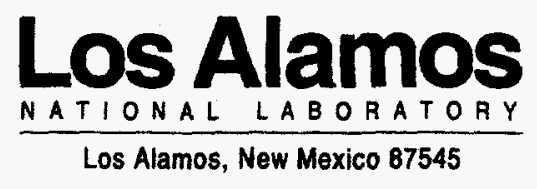





\title{
PROGRESS REPORT ON COLLOID-FACILITATED TRANSPORT AT YUCCA MOUNTAIN
}

\author{
Yucca Mountain Site Characterization Program Milestone 3383
}

by

I.R. Triay, C. Degueldre, A.O. Wistrom, C.R. Cotter, and W.W. Lemons

\begin{abstract}
To assess colloid-facilitated radionuclide transport in groundwaters at the potential nuclear waste repository at Yucca Mountain, it is very important to understand the generation and stability of colloids, including naturally occurring colloids. To this end, we measured the colloid concentration in waters from Well $\mathrm{J}-13$, which is on the order of $10^{6}$ particles per milliliter (for particle sizes larger than 100 nanometers). At this low particle loading, the sorption of radionuclides to colloids would have to be extremely high before the colloids could carry a significant amount of radionuclides from the repository to the accessible environment. We also performed aggregation experiments to evaluate the stability of silica (particle diameter: $85 \mathrm{~nm}$ ) and clay colloids (particle diameter: $140 \mathrm{~nm}$ ) as a function of ionic strength in a carbonate-rich synthetic groundwater. When the concentration of electrolyte is increased to induce aggregation, the aggregation is irreversible and the rate of aggregation increases with increasing electrolyte strength. We used autocorrelation photon spectroscopy to estimate the rate of particle aggregation for both types of colloids. By relating the measured aggregation rate to the Smoluchowski rate expression, we determined the stability ratio, $W$. Aggregation of silica particles and kaolinite clay particles decreased dramatically for an electrolyte concentration, $C_{\mathrm{NaCl}}$, below $300 \mathrm{mM}$ and $200 \mathrm{mM}$, respectively.
\end{abstract}




\section{INTRODUCTION}

An understanding of colloid generation, stability, and transport along potential flowpaths is essential in determining whether colloids will significantly increase radionuclide releases from a potential high-level nuclear waste repository at Yucca Mountain to the accessible environment (Triay et al. 1994). In this report, we concentrate on exploring the generation and stability of colloids in groundwaters at Yucca Mountain. We determined the concentration of colloids in water from Well J-13 and studied the stability of clay and silica colloids in solutions similar to Yucca Mountain groundwaters.

To ascertain the conditions under which colloids would remain in suspension, we performed a series of laboratory aggregation experiments to determine the stability of colloids in synthetic and natural groundwaters as a function of groundwater chemistry. We used the results of our experiments to calculate particle-aggregation rate constants and to establish the stability of colloids. From the standpoint of colloid-facilitated transport to the accessible environment, only stable suspensions, suspensions that exhibit reversible aggregation, and suspensions that exhibit exponential aggregate growth at a comparable time scale as advective transport are of concern. Consequently, the stability of a particulate suspension is a question of the kinetics of aggregation as well as of the structure of the resulting aggregate. In this report, we also propose a strategy, including data collection, for performance assessment calculations that can be used to evaluate the importance of colloid-facilitated radionuclide transport at Yucca Mountain.

\section{J-13 Well Construction}

Harrar et al. (1990) concluded that there is considerable justification for the use of Well J-13 water as a baseline, or reference, water for the Yucca Mountain Project investigations. Part of the justification is their conclusion that a major portion of the water produced by Well J-13 originates in the Topopah Spring Member of the Paintbrush Tuff (which is the same stratigraphic unit as the one proposed for the repository).

Well $\mathrm{J}-13$ is a water-supply well located in Fortymile Wash (east of Yucca Mountain); details of its construction and penetration levels are presented in Figure 1 (reproduced from Harrar et al. 1990). The total depth of the well is 3,500 feet, and it has been producing since its completion in 1963. Inspection of the construction diagram reveals perforations from a long section below the Topopah Spring Member starting at 2,690 feet. However, because of a discrepancy in the records concerning the well configuration (Harrar et al. 1990), it is not clear whether the entire length of the 5.5-inch liner below 1,499 feet is slotted or whether only the interval shown in the figure below $2,690 \mathrm{ft}$. is open. Resolving this discrepany is not very important because there is no cement behind the liner, thus providing access to the well to any fluids entering the borehole below about 1,550 feet. However, hydraulic tests performed on the well yielded transmissivities 


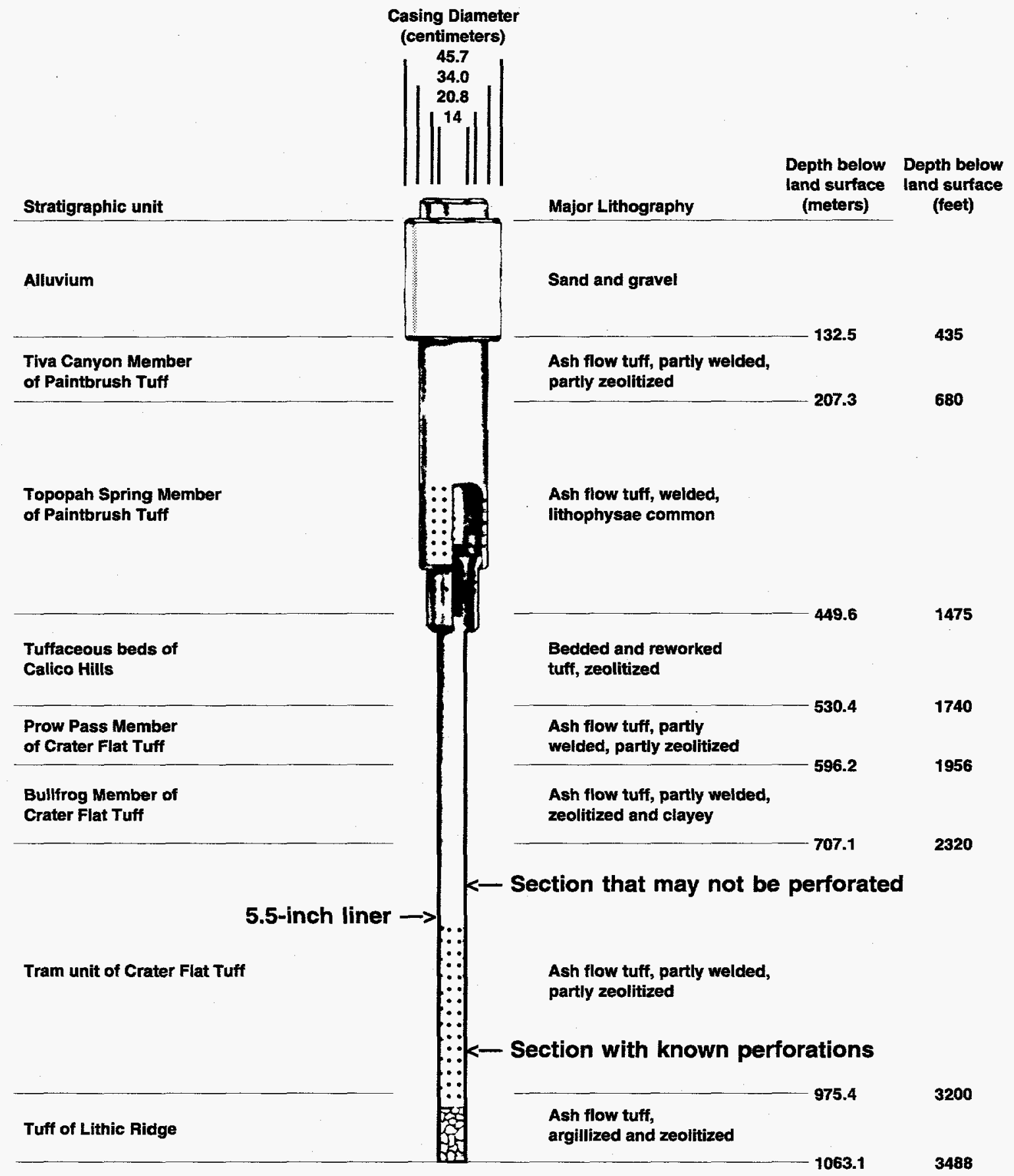

Figure 1. Well J-13. The construction diagram and lithologic units penetrated (reproduced from Harrar et al. 1990). 
that indicated that only about $20 \%$ of the flow may come from other formations, such as the tuffaceous beds of Calico Hills, the three Crater Flat Tuff members, and Tuff of Lithic Ridge.

\section{Groundwater Chemistry of Wells J-13 and UE-25p \#1}

Although water from the repository site may flow toward Well J-13, most of the well water probably comes from subsurface flow and infiltration along Fortymile Wash (Harrar et al. 1990). Water from Well UE-25p \#1 (located roughly midway between Yucca Mountain and Well J-13 at a ground-level elevation about 100 meters higher than Well J-13) originates in the Paleozoic aquifer. Water from Wells J-13 and UE-25p \#1 seem to bound the chemistry of the Yucca Mountain groundwaters (Meijer 1992), and the chemistry of these two groundwaters is given in Appendix A. Both are essentially sodium bicarbonate waters. The other cations are calcium, potassium, and magnesium; the other anions are sulfate, chloride, nitrate, and fluoride; and the other major constituent is silica. The ionic strength of the UE-25p \#1 water is higher than that of the J-13 water. Both waters are oxidizing (Ogard and Kerrisk 1984).

The chemistry of the waters from Wells J-13 and UE-25p \#1 is summarized in Figures 2 and 3, respectively. The Well J-13 data, shown as the front curve in Figure 2, are the average of the chemical analysis of 19 water samples collected between 1963 and 1987 by five different organizations (Los Alamos National Laboratory, U.S. Geological Survey, Lawrence Livermore National Laboratory, Argonne National Laboratory, and Westinghouse-Hanford Company). Analysis of these results led Harrar et al. (1990) to conclude that the water chemistry of Well J-13 did not change between 1963 and 1987. Comparison of the results of Harrar for the period from 1963 to 1987 with similar analyses of water collected in 1992 and 1993 (also shown in Figure 2) indicates that the chemistry of the water in Well J-13 has been stable for 30 years.

We also analyzed aliquots of the groundwaters before and after filtration. Comparison of these results (Figures 2 and 3) indicates that filtration does not cause compositional changes in the water. The $\mathrm{pH}$ of water from both Wells J-13 and UE-25p \#1 is $\sim 7$ when measured at the site; however, upon receipt at Los Alamos, water samples are equilibrated with the atmosphere, resulting in an increase in $\mathrm{pH}$ of Well J-13 water to 8.5 and of Well UE-25p \#1 water to 9. The reason for the $\mathrm{pH}$ increase is $\mathrm{CO}_{2}$ evolution. Some of the J-13 water analysis summarized by Harrar et al. (1990) was performed on site. Although no changes in the J-13 water chemistry seem to result from $\mathrm{CO}_{2}$ evolution and filtration, findings reflected in Figure 3 indicate that $\mathrm{CO}_{2}$ evolution causes a decrease in both bicarbonate and calcium concentrations (implying calcite precipitation) in the water from Well UE-25p \#1.

Comparison of the water chemistry data for Wells J-13 and UE-25p \#1 indicates that determination of colloid concentration in water from Well J-13 would likely provide conservative estimates of the colloid concentration in Yucca Mountain groundwaters (given that colloid stability decreases with increasing groundwater ionic strength). 


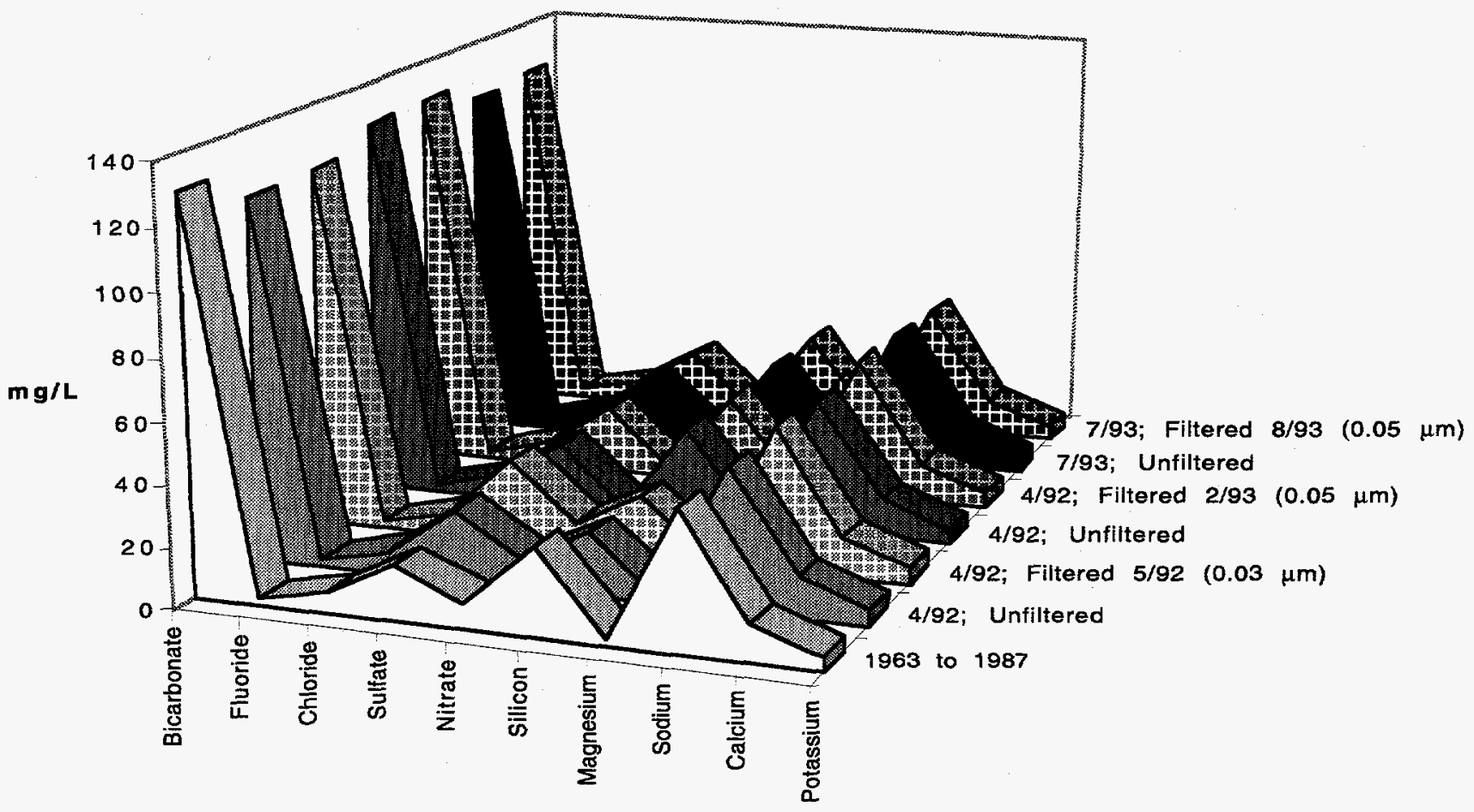

Figure 2. Chemical analysis of Well J-13 water. The curves show minimal compositional changes as a function of collection date and filter size. No calcite precipitation is apparent upon transporting water and letting it stand at Los Alamos.

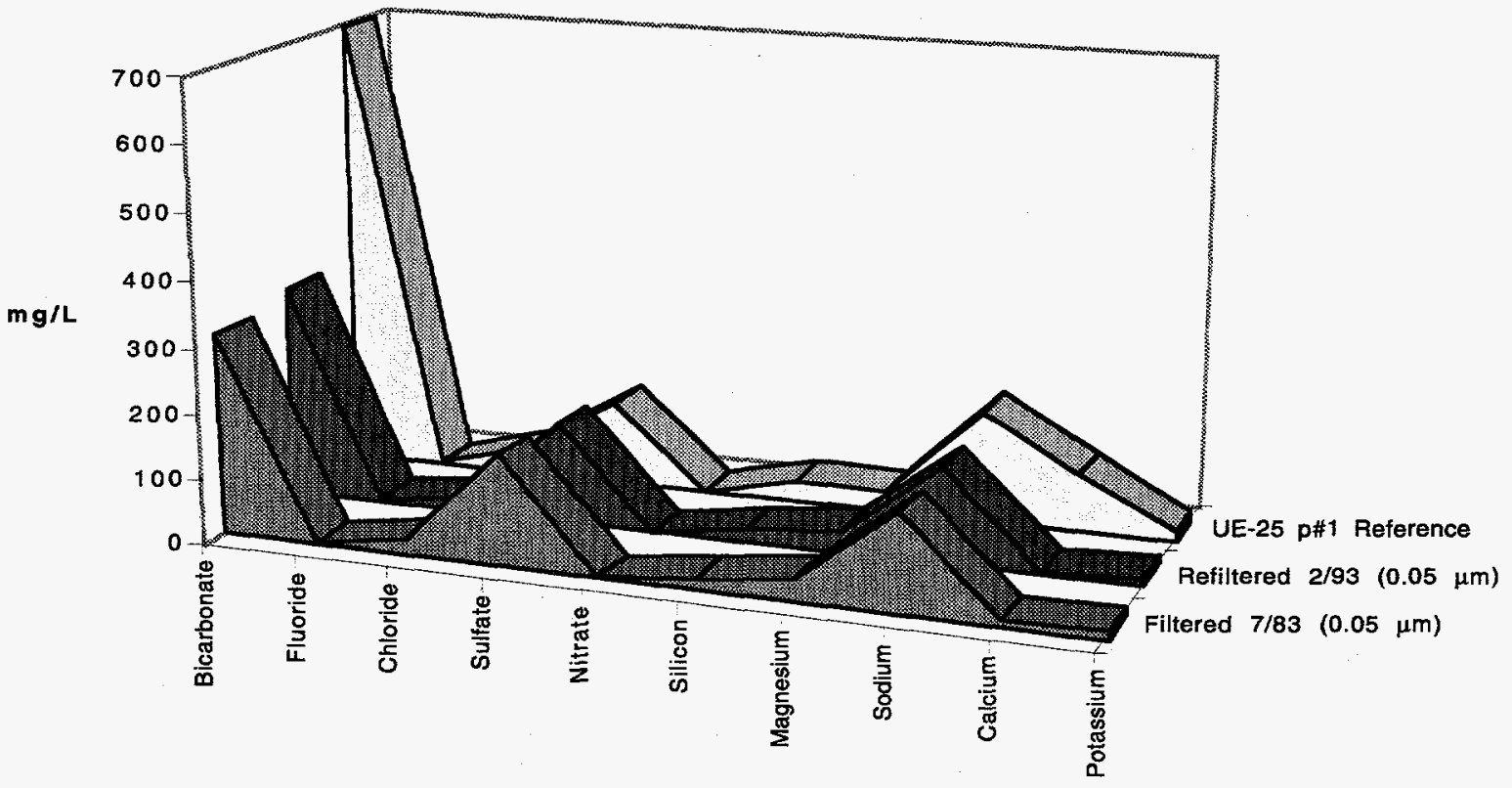

Figure 3. Chemical analysis of Well UE-25p \#1 water. The curves show an apparent calcite precipitation after collection but minimal compositional changes thereafter. 


\section{Collection Procedure}

Los Alamos National Laboratory staff collected samples from Well $\mathrm{J}-13$ to assess the particle size distribution in this water. The apparatus used for this effort, shown in Figure 4, incorporates serial filters of three different sizes to filter the water. Before and after each filtration, water samples were obtained in two different types of containers: borosilicate glass and Teflon. Some of the samples were diluted with Nanopure water immediately after collection at a volume ratio of Nanopure water to J-13 well water of 3 to 1 . Collected samples were assigned barcodes SPC00503113 through SPC00503124 and sent to the Colloid Laboratory at the Paul Scherrer Institute (PSI) in Switzerland for analysis. All samples were collected in duplicate; upon receipt, one of each type of sample was acidified to a $\mathrm{pH}$ of 4 . Sample traceability for this water collection is given in Yucca Mountain Project (YMP) Water Binder II, TWS-INC11-93-08.

\section{Colloid Generation Principles}

According to the theory of colloid generation, natural colloids are primarily generated by the physical fragmentation and erosion of components of the rock in contact with the water (Degueldre 1994).

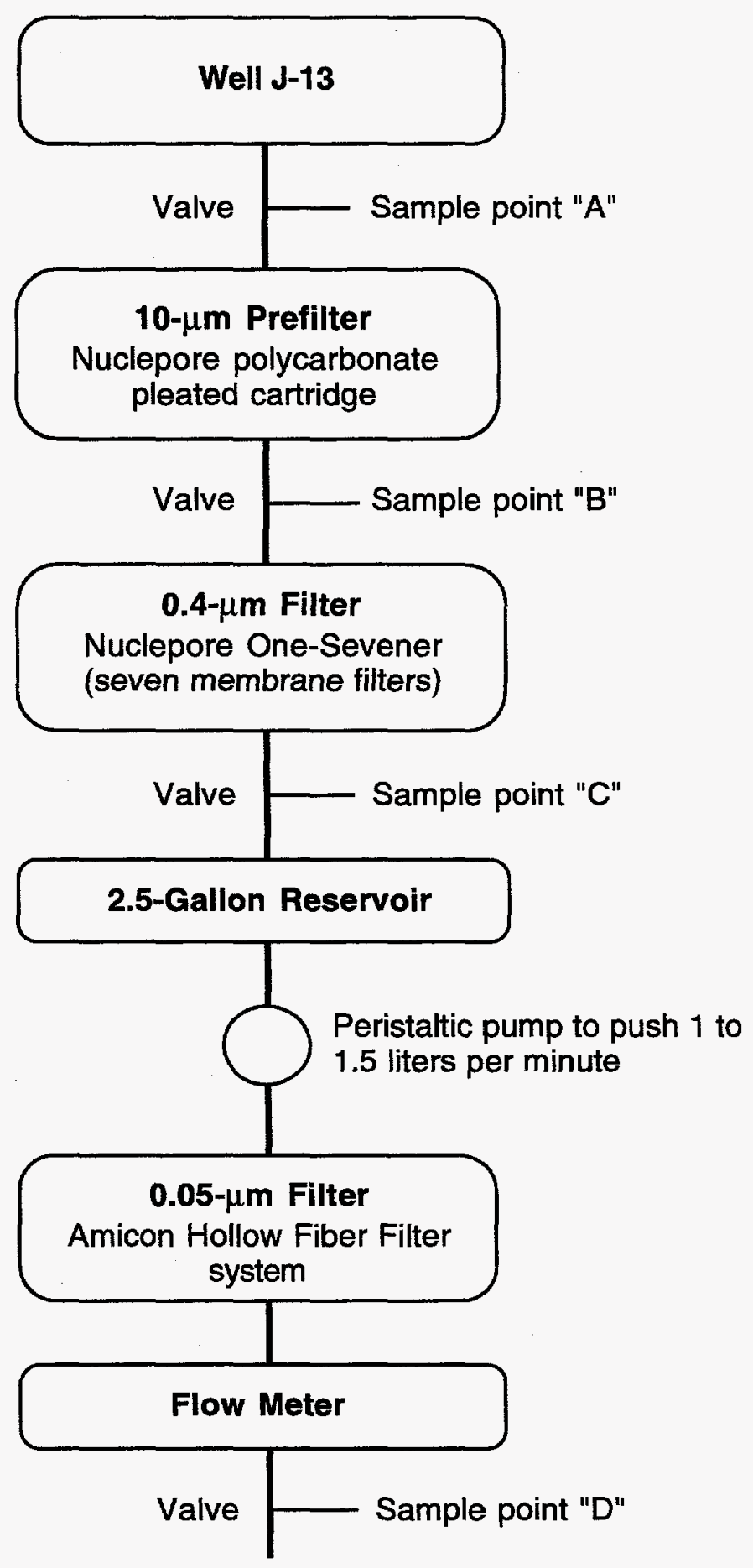

Figure 4. Colloid sampling. Flow diagram of the colloid sampling apparatus at Well J-13. 
The colloid size distribution is continuous and may be described by a Pareto power law:

$$
\frac{\mathrm{d}[\text { coll }]}{\mathrm{d} \phi}=A \cdot \phi^{-b} \text {, }
$$

where $A$ and $b$ are constants, $\phi$ is colloid size in terms of the unit size (here 1 nanometer), and [coll] is the cumulative colloid concentration for size $\phi$ in particles per milliliter $\left(\mathrm{pt}^{\cdot} \mathrm{mL}^{-1}\right)$. When $b>1$, the cumulative colloid concentration is given as follows for sizes ranging from $\phi_{(\mathrm{m})}$, for the smallest size analyzed, to $\phi_{(\mathrm{M})}$, for the largest size analyzed:

$$
[\mathrm{coll}]=\frac{A}{1-b} \cdot\left\{\phi_{(\mathrm{m})}^{1-b}-\phi_{(\mathrm{M})}^{1-b}\right\} .
$$

Experimentally, an integrated colloid concentration, given by Equation 2, can be determined over a range from a low value of $\phi$, such as the detection limit, to a maximum size, such as 1000 nanometers, above which colloids are not found in significant concentrations. The integration constant is zero.

By assuming an average colloid density, $\rho$, and spherical colloids, determination of the colloid concentration (in terms of mass per unit volume) is possible using:

$$
\frac{\mathrm{d} \overline{[\mathrm{coll}]}]}{\mathrm{d} \phi}=\frac{\rho \cdot \pi \cdot \phi^{3}}{6} \cdot \frac{\mathrm{d}[\text { coll }]}{\mathrm{d} \phi},
$$

where $\overline{[\text { coll }]}$ may be expressed in micrograms per milliliter $\left(\mu \mathrm{g} \cdot \mathrm{mL}^{-1}\right)$.

A surface-complexation capacity may be estimated assuming that the colloids are spherical. Two hypotheses for site distributions are suggested. One assumes that surface complexation occurs at the surface of the spherical colloids with an area site density, $\Delta$, in sites per square nanometer; the second considers the spherical colloids as nanoporous entities with a volume site density, $\Delta^{\prime}$, in sites per cubic nanometer. Both minimum (min) and maximum (max) capacities are evaluated using the following equations:

$$
\begin{aligned}
& \left.\frac{\delta[\text { site }]}{\delta \phi}\right|_{\min }=\pi \cdot \phi^{2} \cdot \Delta \cdot \frac{\mathrm{d}[\text { coll }]}{\mathrm{d} \phi} \text {, and } \\
& \left.\frac{\delta[\text { site }]}{\delta \phi}\right|_{\max }=\frac{\pi \cdot \phi^{3}}{6} \cdot \Delta^{\prime} \cdot \frac{\mathrm{d}[\text { coll }]}{\mathrm{d} \phi} .
\end{aligned}
$$

\section{Analysis of Colloid Concentration in J-13 Well Water}

At the Colloid Laboratory at the PSI, the colloid concentration in J-13 well water was determined by laser particle counting, a technique described previously (Degueldre 1994). After significant dilution in ultrapure water, the natural particles from the groundwater were counted with a Horiba (PLC311) unit and analyzed with respect to size according to the intensity of scattered light that 
the particles produce in the unit laser beam (argon, $10 \mathrm{~mW}$ ). Information is displayed in a cumulative distribution:

$$
[\text { coll }]=\int_{\phi_{(\mathrm{m})}}^{\phi_{(\mathrm{M})}} \frac{\mathrm{d}[\text { coll }]}{\mathrm{d} \phi} \cdot \mathrm{d} \phi
$$

where $\phi_{(\mathrm{m})}$ and $\phi_{(\mathrm{M})}$ are, respectively, the smallest and largest sizes analyzed.

To calculate the colloid concentration (either as particle concentration, [coll], or as mass concentration, $\overline{[\text { coll }]}$ ) for a given size range and to calculate normal size distribution (either as $\mathrm{d}[$ coll $] \cdot \mathrm{d} \phi^{-1}$ or as $\mathrm{d} \overline{[\mathrm{coll}]} \cdot \mathrm{d} \phi^{-1}$ ), the results from these analyses were treated (by J. C. Loizeau at the University of Geneva) with the PSI code COLIAT (for colloid linear analytical treatment). Two COLIAT options, both based on Equations 1 to 3, are available. The first option considers $A$ and $b$ as constant over the size range; the second option considers $A$ and $b$ as a function of $\phi$ (although constant in the interval from $\phi$ to $\phi+\Delta \phi$ ). Both options assume that all colloids are spherical. Equation 3 relates the mass and particle concentrations of colloids for a size range on the basis of colloid density. The resulting linear plot is conservative for the small colloids because, in principle, $b$ decreases when colloid size decreases.

\section{RESULTS AND DISCUSSION OF COLLOID CONCENTRATION DETERMINATIONS}

The following observations were made during the analysis of the $\mathrm{J}-13$ well water:

- The colloid concentration in the acidified samples was the same as the colloid concentration in the unacidified samples. Thus, removing the water from the subsurface does not seem to cause precipitation of calcium carbonate or other solids that may change the amount of colloids measured in the J-13 well water.

- The colloid concentration in samples placed in Teflon containers was smaller than in samples placed in glass containers, probably because of particle adsorption to the walls of the Teflon containers. Thus, a glass container seems to be better than a Teflon container for collecting water samples. A similar result was found during the Grimsel Colloid Exercise (Degueldre et al. 1990).

- The measured colloid concentration in the filtered samples was larger than in the unfiltered samples. Therefore, collecting water from the well itself without further filtration seems to be the best collection method because filters may add particles to the collected water.

Table I summarizes the concentration and characteristics of the colloids in the water from Well J-13 (assuming $\rho=2 \mathrm{~g} \cdot \mathrm{mL}^{-1}$ ). The Pareto power law (Equation 1) yields a value of 3.76 for $b$ and $-3.2 \times 10^{12} \mathrm{pt} \cdot(\mathrm{mL})^{-1}$ for $A$. As suggested earlier (Degueldre 1994), when $b=4$, colloids 
may have been generated by erosion, including, for example, rock multifragmentation. In natural media, however, specific attachment, nucleation, and aggregation may modify the values of $A$ and $b$. In the case discussed earlier, when $b=4$, no aggregation takes place; when $b<4$, aggregation may have occurred.

Table I. Concentration and Characteristics of Colloids in J-13 Well Water

\begin{tabular}{|c|c|c|c|c|}
\hline $\begin{array}{l}\text { Size } \\
(\mathrm{nm})\end{array}$ & $\begin{array}{c}\text { Number } \\
\text { concentration } \\
\text { of colloids } \\
\left(\mathrm{pt} \cdot \mathrm{mL}^{-1}\right) \\
\end{array}$ & $\begin{array}{c}\text { Mass } \\
\text { concentration } \\
\text { of colloids } \\
\left(\mathrm{ng} \cdot \mathrm{mL}^{-1}\right)^{*}\end{array}$ & $\begin{array}{l}\text { Minimum site } \\
\text { concentration of } \\
\text { colloids } \\
\left(\text { nmoles } \cdot \mathrm{mL}^{-1}\right)^{* *}\end{array}$ & $\begin{array}{l}\text { Maximum site } \\
\text { concentration of } \\
\text { colloids } \\
\left(\text { nmoles } \cdot \mathrm{mL}^{-1}\right)^{* * *}\end{array}$ \\
\hline$>100$ & $4.2 \times 10^{6}$ & 30.6 & $1.6 \times 10^{-3}$ & $7.6 \times 10^{-2}$ \\
\hline$>200$ & $3.6 \times 10^{5}$ & 23.1 & $8.2 \times 10^{-4}$ & $5.8 \times 10^{-2}$ \\
\hline$>500$ & $4.7 \times 10^{4}$ & 11.0 & $2.4 \times 10^{-4}$ & $2.7 \times 10^{-2}$ \\
\hline
\end{tabular}

*The mass concentration was calculated for a size range of 100 to 1000,200 to 1000 , and 500 to $1000 \mathrm{~nm}$, respectively, using an average colloid density of $2 \mathrm{~g} / \mathrm{mL}$.

**Site concentrations were calculated using site densities of 3 sites/nm (minimum) and 3 sites/nm (maximum).

Water from Well J-13 has previously been used for particulate analysis, and the results have been reported by Ogard (1987). He diverted water from Well J-13 into a mobile laboratory at a rate of $\sim 1 \mathrm{~L} \cdot \mathrm{min}^{-1}$ and used a prefilter to remove particles larger than $10 \mu \mathrm{m}$. He then filtered the water through a large stainless-steel One-Sevener Nuclepore Filter Assembly, loaded with seven 0.4- $\mu \mathrm{m}$ membrane filters, mounted in parallel. Approximately one-half of the water filtered through this assembly subsequently passed through an Amicon Hollow Fiber Filter system, which further removed particulates with diameters greater than $\sim 5 \mathrm{~nm}$. Thus, the particle size of the material caught by the $0.4-\mu \mathrm{m}$ filter system should range from 0.4 to $10 \mu \mathrm{m}$, or 400 to $10,000 \mathrm{~nm}$ (largesize fraction), and the particle size of the material caught by the 5-nm filter system should range from 0.005 to $0.4 \mu \mathrm{m}$, or 5 to $400 \mathrm{~nm}$ (small-size fraction).

A filtration run conducted for 14 days yielded a sediment concentration for the large-size fraction of $\sim 2.7 \times 10^{-5} \mathrm{~g} \cdot \mathrm{L}^{-1}$, and a sediment concentration that was only $1 \%$ of this value on the small-size fraction. The large-size particulate fraction was removed from the filter system with ultrasonic treatment, dissolved in acid, and analyzed for cation composition by emission spectroscopy. The weight percentages were: silicon, $60 \%$; iron, $20 \%$; calcium, $11 \%$; and aluminum, 4\%. A similar analysis of the small-size particulate fraction, collected from the hollow-fiber system by backflushing with Nanopure water, yielded: sodium, $44 \%$; silicon, $42 \%$; calcium, $8 \%$; and iron, $4 \%$. The iron-rich particulates are suspected to be the result of contamination from the steel piping and pumping systems used in the well. 
There is good agreement between the results obtained by Ogard and the results presented in this study. We found the concentration of colloids larger than $0.2 \mu \mathrm{m}(200$ to $1000 \mathrm{~nm})$ to be $2.3 \times 10^{-5} \mathrm{~g} \cdot \mathrm{L}^{-1}$, which agrees with Ogard's value of $2.7 \times 10^{-5} \mathrm{~g} \cdot \mathrm{L}^{-1}$ for the concentration of colloids larger than $0.4 \mu \mathrm{m}$. Ogard assessed the importance of particulates in the transport of radionuclides at Yucca Mountain, basing his assessment on this latter value for the particulate concentration in J-13 water and on the reversible sorption of radionuclides onto colloidal species. He concluded that particulates in J-13 well water would have to exhibit a sorption distribution coefficient greater than $4 \times 10^{6} \mathrm{~mL}^{-1}$ for a given radionuclide in order for pseudocolloids to contribute more than $10 \%$ to the total amount of radionuclides migrating through Yucca Mountain. Ogard points out that sorption distribution coefficients of that magnitude have not been observed for sorption onto tuff of any radionuclide in the high-level waste.

\section{EXPERIMENTAL PROCEDURES FOR STABILITY EXPERIMENTS}

For the stability investigations, we chose particles of kaolinite clay and amorphous silica because of their prevalence in the natural environment, their previous use in aggregation studies, and the requirement that particulate suspensions be made in a consistent and reproducible manner. Silica particles from the Nissan Chemical Co. were cleaned by repeated centrifugation, decanting, and resuspension in ultrafiltered deionized water until the conductivity of the particulate suspension was $40 \mu \mathrm{S} / \mathrm{cm}$ or less for three consecutive washings. Kaolinite clay was acid washed and repeatedly cleaned (van Olphen 1977). The hydrodynamic mean diameter and number concentration were $85 \mathrm{~nm}$ and $1.75 \times 10^{9}$ particles per $\mathrm{mL}$, respectively, for the silica particles and was $200 \mathrm{~nm}$ and $1.59 \times 10^{9}$ particles per $\mathrm{mL}$, respectively, for the kaolinite clay particles.

The chemical composition of the aqueous medium was designed to mimic groundwater compositions at Yucca Mountain (Kerrisk 1987). We prepared particle stock solutions by resuspending the sols in a carbonate-rich solution $\left(0.368 \mathrm{mM} \mathrm{Na}_{2} \mathrm{CO}_{3}+10.600 \mathrm{mM} \mathrm{NaHCO}\right.$ ) having a $\mathrm{pH}$ of 7.8 . All experiments were performed at $27.5^{\circ} \mathrm{C}$. We induced aggregation by adding sufficient $\mathrm{NaCl}$ electrolyte solution to the prepared particulate suspensions to achieve a final $\mathrm{NaCl}$ concentration ranging from 100 to $800 \mathrm{mM}$. We ascribe observed differences in particle-aggregation rates to differences in solution chemistry (ionic strength) and particle composition.

We used autocorrelation photon spectroscopy (APS) to estimate the particle-aggregation rate constant for the early stages of the aggregation process. APS is sensitive to fluctuations in scattered intensity resulting from the Brownian motion of particles. The fluctuations in scattering intensity yield an intensity autocorrelation function in which the mean decay constant can be directly related to a mean diffusion coefficient (Ostrowsky 1988; Brown and Pusey 1975; and Amal et al. 1990). Particle size is related to the mean diffusion coefficient, $D_{\text {mean }}$, by the StokesEinstein relation: 


$$
D_{\text {mean }}=\frac{\mathrm{k}_{\mathrm{B}} T}{3 \pi \eta \phi_{\text {mean }}},
$$

where $\mathrm{k}_{\mathrm{B}}$ is Boltzmann's constant, $T$ is the temperature in Kelvin, $\eta$ is the viscosity of the suspending liquid, and $\phi_{\text {mcan }}$ is the hydrodynamic mean diameter of the particles. Because aggregate growth changes the particle size distribution over time, the rate of aggregation can be estimated using Equation 6 by determining the rate of decrease in the mean diffusion coefficient. The interpretation of diffusion coefficients, and consequently $\phi_{\text {mean }}$, measured by APS is affected by polydispersivity, particle shape, and particle-particle interactions. In this study, we handled the effect of polydispersivity and particle shape on the autocorrelation function satisfactorily by preparing essentially monodispersed particle solutions, which allowed us to discard the higherorder terms of the cumulant method.

For a discrete particle size distribution, the generation of doublets by collisions of primary particles is represented by a second-order rate law (Stumm and Morgan 1981):

$$
\frac{\partial\left[\operatorname{coll}_{\mathrm{I}}\right]}{\partial t}=-k_{\mathrm{II}}\left[\operatorname{coll}_{\mathrm{I}}\right]^{2}
$$

where $k_{\mathrm{II}}$ is the rate constant for doublet formation and [coll $]$ is the number concentration of primary particles. Aggregation rate constants, $k_{\Pi}$, were calculated from the initial slope of a plot of $\phi_{\text {mean }}$ as a function of time, $t$, using:

$$
\phi_{\text {mean }} \cdot k_{\mathrm{II}}=\frac{1}{F \cdot\left[\operatorname{coll}_{\mathrm{I}}\right]_{(t=0)}} \cdot \frac{\partial\left(\phi_{\text {mean }}\right)}{\partial t}
$$

where $F$ is an optical factor and $\left[\operatorname{coll}_{\mathrm{I}}\right]_{(\mathrm{t}=0)}$ is the initial number concentration of primary particles (Virden and Berg 1992). Because partial aggregation of the initial dispersion affects the analysis of the aggregation kinetics, we implemented a correction procedure to account for the initial size distribution of the aggregates. The correction was accomplished by projecting the slope of a plot of the function $\phi_{\text {mean }}$ to a time point where $\phi_{\text {mean }}$ corresponds to the initial (monodispersed) suspension.

APS measurements were made with a Brookhaven laser light-scattering system (Brookhaven Instruments, Holtsville, New York) equipped with an Innova 90 Argon laser (Coherent Laser Products Division, Palo Alto, California) operating at $\lambda=514 \mathrm{~nm}$ and 0.5 to $1.0 \mathrm{~W}$. Sampling times are dependent on particle concentration and ionic strength of the medium. Experimental run times for the aggregation experiments were typically 60 minutes (longer run times are necessary for highly stable colloids). Measurements of the hydrodynamic diameter, $\phi_{\text {mean }}$, were made every minute using a sampling duration of 30 seconds. All measurements were made at a scattering angle of $90^{\circ}$. 


\section{RESULTS AND DISCUSSION OF STABILITY EXPERIMENTS}

The experimental results, reported in Figures 5 and 6, characterize the aggregation process of silica and kaolinite clay. Aggregation of silica particles and kaolinite clay particles decreased dramatically for an electrolyte concentration, $C_{\mathrm{NaCl}}$, below $300 \mathrm{mM}$ and $200 \mathrm{mM}$, respectively.

However, it is possible that reversible aggregation occurs in this concentration range if a secondary minimum, distinguished by the absence of a potential barrier in the potential curve, is

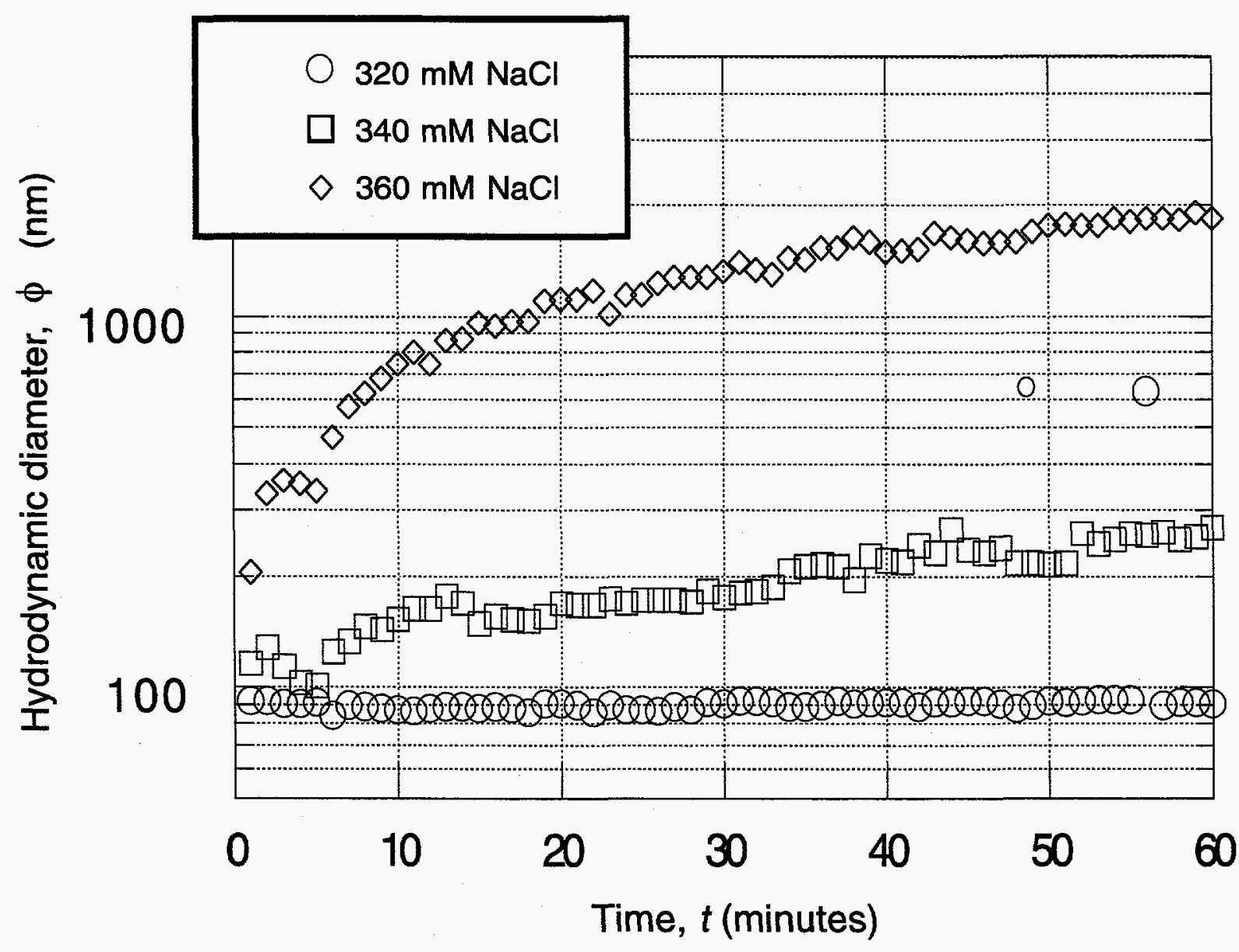

Figure 5. Aggregate growth for silica particles. Here, $\phi_{\text {mean }}=85 \mathrm{~nm}$ at $t=0$, and the $\mathrm{pH}$ of the solution is 7.8. The flatness of the bottom curve $\left(C_{\mathrm{NaCl}}=320 \mathrm{mM}\right)$ indicates a steady-state condition with no aggregation; the middle curve $\left(C_{\mathrm{NaCl}}=340 \mathrm{mM}\right)$ shows reaction-limited aggregation (RLA); and the upper curve $\left(C_{\mathrm{NaCl}}=360 \mathrm{mM}\right)$ shows reaction-limited aggregation initially and diffusion-limited aggregation (DLA) in the later stages of growth. 
present (Overbeek 1952). However, the duration of the current set of experiments was too short to resolve aggregate growth at this level of detail (Cametti et al. 1989). When the concentration of electrolyte is increased to induce aggregation, aggregate growth proceeds at an exponential rate, is irreversible, and the rate of aggregation increases with increasing electrolyte strength. The relationship between electrolyte strength and growth rate is evident for kaolinite clay particles at $C_{\mathrm{NaCl}}$ between 100 and $300 \mathrm{mM}$ (as shown in Figure 6). At high electrolyte concentrations, the rate of aggregation slows down abruptly after the initial rapid growth phase. The first stage of exponential growth is characterized by reaction-limited aggregation (RLA), and the second stage of the growth curve is characterized by diffusion-limited aggregation (DLA). The rapid and slow

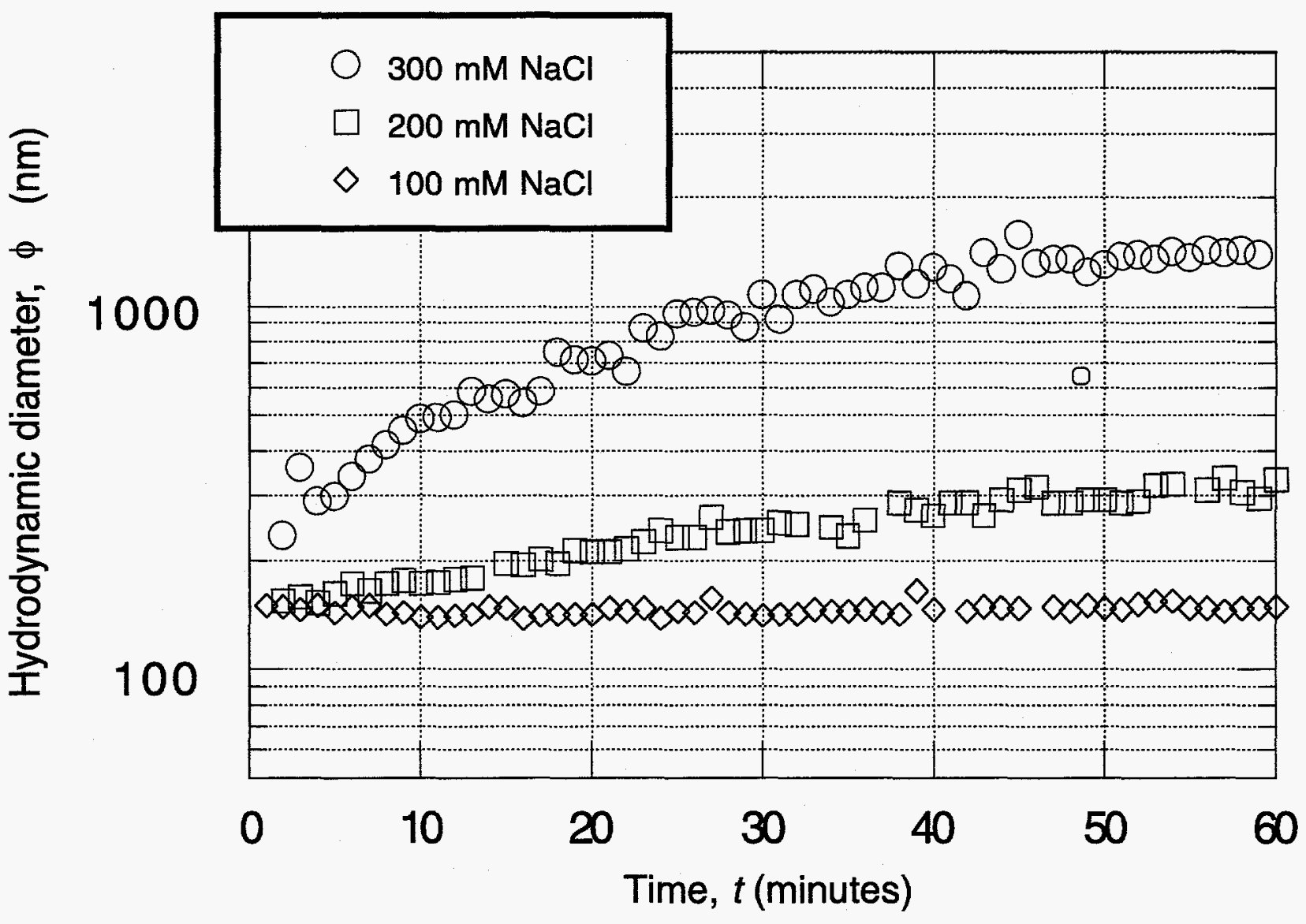

Figure 6. Aggregate growth for kaolinite clay particles. Here, $\phi_{\text {mean }} \sim 200 \mathrm{~nm}$ at $t=0$; the $\mathrm{pH}$ is 7.8. The lowest curve $\left(C_{\mathrm{NaCl}}=100 \mathrm{mM}\right)$ suggests a steady-state condition with no aggregation; the middle curve $\left(C_{\mathrm{NaCl}}=200 \mathrm{mM}\right)$ shows reaction-limited aggregation (RLA); and the upper curve $\left(C_{\mathrm{NaCl}}=\right.$ $300 \mathrm{mM}$ ) shows reaction-limited aggregation initially and diffusion-limited aggregation (DLA) later. 
regimes of aggregation have been observed in various particulate systems, such as polystyrene, gold, and silica colloids (Cametti et al. 1989).

Aggregation rates are readily expressed in terms of stability, $W$, defined as the ratio between the Smoluchowski rate constant, $k_{\text {smol }}$, and the experimentally attained rate constant:

$$
W=\frac{k_{\text {smol }}}{k_{\text {II }}},
$$

where $W$ is dimensionless and $k_{\text {smol }}$ is obtained from the Smoluchowski equation for doublet formation:

$$
k_{\mathrm{smol}}=\frac{8 \mathrm{k}_{\mathrm{B}} T}{3 \mu},
$$

where $T$ is absolute temperature and $\mu$ is the dynamic suspension viscosity (Stumm and Morgan 1981). The effect of varying electrolyte concentration is shown in Figure 7.

Kaolinite clay particles are destabilized at a lower electrolyte concentration than are silica particles. Also evident is the gradual increase in stability of the clay particles, compared with the abrupt transition from unstable to stable behavior exhibited by the silica particles. Kaolinite clay is characterized by the negative surface charge on the clay face, which is a result of isomorphic substitution and the electronegative character of the oxygen atoms, and by a positive charge on the mineral edges, which is a result of exposed cations. Thus, when the clay minerals are suspended in waters with low electrolyte concentration, collisions may produce aggregates having an open and porous structure. At higher electrolyte concentrations, the repulsive forces may be suppressed to allow aggregation into denser aggregates.

For slow aggregation processes, the time scale for aggregate rearrangement and aggregate consolidation is long compared with the time scale of collision, whereas for rapid, or irreversible aggregation, aggregate rearrangement is less probable. If aggregate consolidation does take place, then aggregates having a uniform surface-charge distribution could form more compact and dense clusters during slow aggregation and more open clusters under fast aggregation. Consequently, colloid stability is a function of particle charge, of surface-charge distribution, and of aggregation kinetics (Lips and Duckworth 1988). The experimentally determined particleaggregation constants may be used in transport models to assess the mobility of subsurface colloids along given flowpaths as a function of groundwater chemistry. 


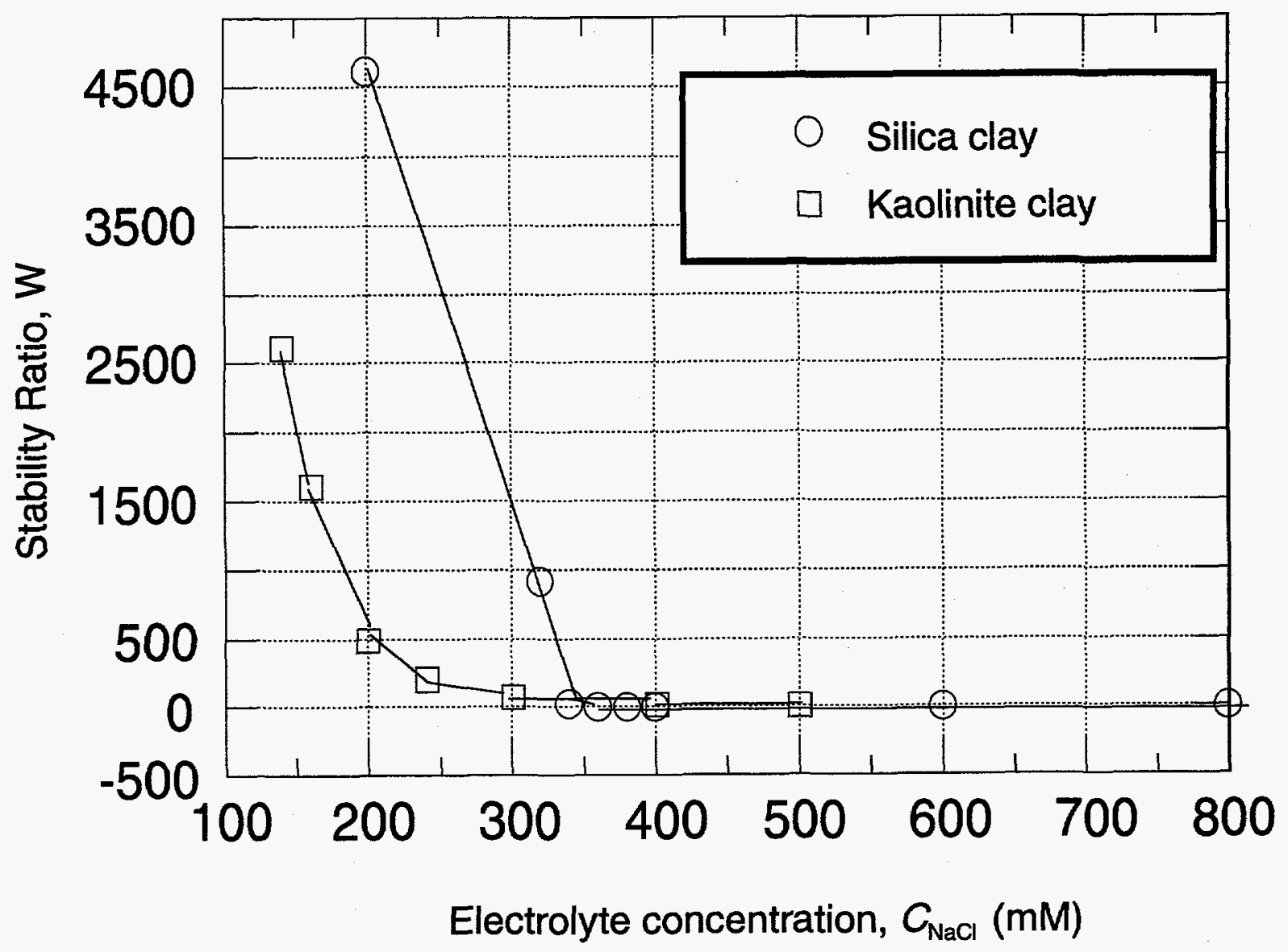

Figure 7. Stability curves. The stability ratio, $W$, is shown for silica and kaolinite clay particles in synthetic groundwater at a $\mathrm{pH}$ of 7.8 as a function of sodium chloride electrolyte concentration, $C_{\mathrm{NaCl}}$. The $k_{\text {smol }}$ factor in the stability ratio $\left(W=k_{\text {smol }} / k_{11}\right)$ remains constant with changing electrolyte concentration, but $k_{11}$, the kinetic rate factor for doublet formation, varies and, in fact, approaches $k_{\text {smol }}$ in value as the electrolyte concentration increases. As a result, $W$ approaches a minimum value of 1 at high electrolyte concentrations. 


\section{CONCLUSIONS AND SUMMARY OF DATA NEEDS FOR COLLOID INVESTIGATIONS}

A sensitivity analysis study to assess important parameters for colloid-facilitated radionuclide transport can be performed. The following assumptions could be made for this calculation.

1. The colloids generated are clays, silica, and iron oxides.

2. The amount of total organic carbon (TOC) in groundwaters is negligible.

3. The stability ratio of the colloids can be estimated on the basis of the data observed for model colloids.

4. The sorption of radionuclides onto colloids $\left(K_{\mathrm{p}}\right)$ can be calculated on the basis of available $K_{\mathrm{d}}$ values (or on the basis of $K_{\mathrm{p}}$ values from the literature: $\sim 3 \times 10^{4} \mathrm{~mL} \cdot \mathrm{g}^{-1}$ for the trivalent and tetravalent actinide species).

5. Irreversible sorption of radionuclides onto colloids occurs.

6. No attachment of colloids onto fracture walls occurs.

7. Colloids are excluded from tuff pores by their size and charge.

Depending on what parameters are the most important in controlling colloid-facilitated radionuclide transport, the following data needs may exist:

- Experimental determination of type of colloids generated from spent fuel (to address assumption 1).

- Study of Yucca Mountain as its own analog (to address assumption 1).

- Experimental determination of total organic carbon (TOC) in groundwaters on line (to address assumption 2).

- Experimental determination of colloid population and size distributions in groundwaters using off-line particle counting techniques (to address assumptions 3 and 5 , because $K_{\mathrm{p}}$ depends on particle size).

- Experimental determination of selected $K_{\mathrm{p}}$ values for clay and silica using likely groundwaters (to address assumption 5). 
- Experimental determination of the degree of colloid attachment to fracture walls using fractured tuff columns (to address assumption 6).

- Transport field experiment (under saturated conditions) in C Wells (to address assumption 7).

- Transport field experiment (under unsaturated conditions) using nuclear test at the Nevada Test Site as a source term (to address assumption 7).

\section{ACKNOWLEDGMENTS}

This work was supported by the Yucca Mountain Site Characterization Project Office of Los Alamos National Laboratory as part of the Civilian Radioactive Waste Management Program of the U.S. Department of Energy. The Los Alamos data tracking number for this record package is LA000000000128.001

\section{REFERENCES}

Amal, R., J.R. Coury, J.A. Raper, W.P. Walsh, and T.D. Waite. 1990. Structure and kinetics of aggregating colloidal hematite. Colloids and Surfaces 46: 1.

Brown, J.C., and P.N. Pusey. 1975. Photon correlation study of polydisperse samples of polystyrene in cyclohexane. J. Chemical Physics 62(3): 1136.

Cametti, C.P., P. Codastefano, and P. Tartaglia. 1989. Aggregation kinetics in model colloidal systems: A light scattering study. J. Colloid and Interface Science 131(2): 409-422.

Degueldre, C., G. Longworth, V. Moulin, and P. Vilks. 1990. Grimsel Colloid Exercise: An international intercomparison exercise on the sampling and characterisation of groundwater colloids. PSI/NAGRA/CEDRA/CISRA technical report 90-01 (January 1990).

Degueldre, C. 1994. Colloid properties in groundwaters from crystalline formations. PSI/NAGRA report NTB-92-05.

Harrar, J., J. Carley, W. Isherwood, and E. Raber. 1990. Report of the committee to review the use of J-13 well water in the Nevada nuclear waste storage investigations. Lawrence Livermore National Laboratory report UCID-21867.

Kerrisk, J. 1987. Groundwater chemistry at Yucca Mountain, Nevada, and vicinity. Los Alamos National Laboratory report LA-10929-MS. 
Lips, A., and R.M. Duckworth. 1988. Combined study of coagulation kinetics and close-range aggregate structure. J. Chem. Soc. Faraday Trans. 1 84(4): 1223-1242.

Meijer, A. 1992. A strategy for the derivation and use of sorption coefficients in performance assessment calculations for the Yucca Mountain site. In Proceedings of the DOE/Yucca Mountain Site Characterization Project Radionuclide Adsorption Workshop at Los Alamos National Laboratory, September 11-12, 1990, Los Alamos National Laboratory report LA-12325-C, pp. 9-40 (August 1992).

Ogard, A.E., and J.F. Kerrisk. 1984. Groundwater chemistry along flow paths between a potential repository site and the accessible environment. Los Alamos National Laboratory report LA10188-MS (November 1984).

Ogard, A. 1987. Importance of radionuclide transport by particulate entrained in flowing groundwaters. In Kerrisk , J.F., Groundwater chemistry at Yucca Mountain, Nevada, and vicinity, Los Alamos National Laboratory report LA-10929-MS, pp. 114-118.

Ostrowsky, N. 1988. Particle characterization by photon correlation spectroscopy. In Proceedings of the 6th Particle Size Analysis Conference, April 19-20, 1988, Guildford, U.K.: University of Surrey.

Overbeek, J.T.G. 1952 Stability of hydrophobic colloids and emulsions. In Colloid Science: Vol 1, Irreversible Systems, edited by Kruyt, H.R. Elsivier.

Stumm, W., and J.J. Morgan. 1981. Aquatic Chemistry, 2nd ed. New York: John Wiley and Sons.

Triay, I., A. Simmons, S. Levy, H. Nuttall, B. Robinson, W. Stenkampf, B. Vianni, and S. Nelson. 1994. Colloid-facilitated radionuclide transport at Yucca Mountain. Los Alamos National Laboratory report LA-12779-MS.

van Olphen, H. 1977. An Introduction to Clay Colloid Chemistry, 2nd ed. New York: John Wiley and Sons.

Virden, J.W. and J.C. Berg. 1992. The use of photon correlation spectroscopy for estimating the rate constant for doublet formation in an aggregating colloidal suspension. J. Colloid and Interface Science 141(2): 528-535. 
Appendix A: Chemical Analysis of Water from Wells J-13 and UE-25p \#1

\begin{tabular}{|c|c|c|c|c|c|c|c|}
\hline $\begin{array}{l}\text { Concentrations } \\
\left(\mathrm{mg} \cdot \mathrm{L}^{-1}\right)\end{array}$ & $\begin{array}{c}\text { Collected } 1963 \\
\text { to } 1987\end{array}$ & $\begin{array}{c}\mathrm{J}-13 \\
\text { SPC00007994 } \\
\text { Unfiltered }\end{array}$ & $\begin{array}{c}\mathrm{J}-13 \\
\text { SPC00007994 } \\
\text { Filtered }\end{array}$ & $\begin{array}{c}\mathrm{J}-13 \\
\text { SPC00007995 } \\
\text { Unfiltered }\end{array}$ & $\begin{array}{c}\mathrm{J}-13 \\
\text { SPC00007995 } \\
\text { Filtered }\end{array}$ & $\begin{array}{c}\text { J-13 } \\
\text { SPC00007996 } \\
\text { Unfiltered }\end{array}$ & $\begin{array}{c}\text { J-13 } \\
\text { SPC00007996 } \\
\text { Filtered }\end{array}$ \\
\hline Silicon & 29 & 20 & 20 & 23 & 23 & 30 & 30 \\
\hline Aluminum & & $<0.1$ & $<0.1$ & $<0.3$ & $<0.3$ & $<0.15$ & $<0.15$ \\
\hline Iron & & $<0.01$ & $<0.01$ & $<0.1$ & $<0.1$ & $<0.4$ & $<0.4$ \\
\hline Manganese & & $<0.01$ & $<0.01$ & $<0.1$ & $<0.1$ & $<0.01$ & $<0.01$ \\
\hline Magnesium & 2.0 & 1.7 & 1.6 & 1.7 & 1.6 & 1.9 & 2.0 \\
\hline Calcium & 13.0 & 12.8 & 13.3 & 12.7 & 12.3 & 12.7 & 12.7 \\
\hline Sodium & 46 & 46 & 47 & 46 & 47 & 44 & 47 \\
\hline Potassium & 5.0 & 5.2 & 5.4 & 4.4 & 4.4 & 4.6 & 4.7 \\
\hline Cesium & & $<0.2$ & $<0.2$ & $<0.2$ & $<0.2$ & $<0.2$ & $<0.2$ \\
\hline Lithium & 0.05 & 0.04 & 0.04 & $<0.04$ & 0.04 & 0.46 & 0.05 \\
\hline Carbonate & & 2.5 & 1.5 & & 1.6 & $<0.1$ & $<0.1$ \\
\hline Bicarbonate & 129 & 118 & 119 & 129 & 121 & 126 & 127 \\
\hline Fluoride & 2.2 & 2.3 & 2.2 & 2.2 & 2.3 & 2.3 & 2.4 \\
\hline Chloride & 7.1 & 6.9 & 7.2 & 5.7 & 7.7 & 7.4 & 7.6 \\
\hline Sulfate & 18.4 & 23.0 & 27.0 & 15.0 & 17.0 & 20.6 & 21.4 \\
\hline Nitrate & 8.9 & 9.0 & 8.6 & 15.0 & 7.5 & 1.5 & 1.7 \\
\hline TOC & & 0.44 & 0.58 & & 0.47 & 1.62 & 1.10 \\
\hline $\mathbf{p H}$ & 6.9 & 8.5 & 8.4 & & 8.5 & 8.0 & 7.8 \\
\hline Date Collected & 1963 to 1987 & $4 / 27 / 92$ & $4 / 27 / 92$ & $4 / 27 / 92$ & $4 / 27 / 92$ & $4 / 27 / 92$ & $4 / 27 / 92$ \\
\hline Date Filtered & N/A & N/A & $5 / 8 / 92$ & N/A & $5 / 8 / 92$ & N/A & $2 / 24 / 93$ \\
\hline Filter Size $(\mu \mathrm{m})$ & N/A & N/A & 0.03 & N/A & 0.03 & N/A & 0.05 \\
\hline Results found in: & $\begin{array}{c}\text { UCID-21867, } \\
\text { pages } 4.2 \text { and } \\
4.3\end{array}$ & $\begin{array}{c}\text { TWS-INC11- } \\
9 / 82-49 \\
\text { page } 40\end{array}$ & $\begin{array}{c}\text { TWS-INC11- } \\
9 / 82-49, \\
\text { page } 40\end{array}$ & $\begin{array}{c}\text { TWS-INC11- } \\
9 / 82-49, \\
\text { pages } 34,35\end{array}$ & $\begin{array}{c}\text { TWS-INC11- } \\
\text { 9/82-49, } \\
\text { pages } 34,35\end{array}$ & $\begin{array}{c}\text { TWS-INC-03- } \\
93-02, \\
\text { page C8 }\end{array}$ & $\begin{array}{c}\text { TWS-INC-03- } \\
93-02, \\
\text { page C8 }\end{array}$ \\
\hline
\end{tabular}


Appendix A: Chemical Analysis of Water from Wells J-13 and UE-25p \#1

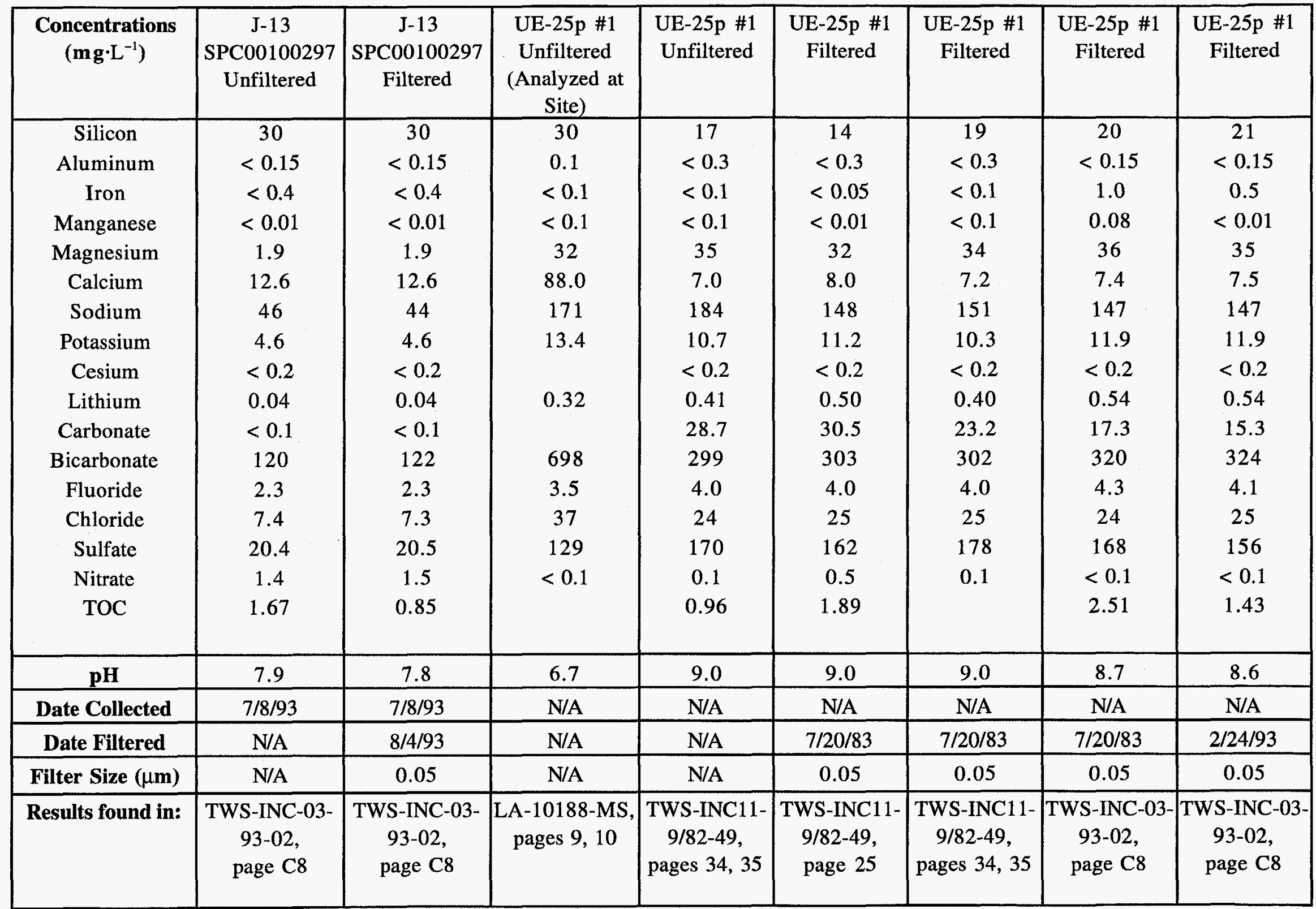

